\title{
SOBRE O SETTLING DO PORTUGUÊS BRASILEIRO
}

\author{
SOBRE EL SETTLING DEL PORTUGUÉS BRASILEÑO \\ ON THE SETTLING OF BRAZILIAN PORTUGUESE
}

\author{
Luiz Henrique Queriquelli* \\ Universidade Federal de Santa Catarina - UFSC, Florianópolis, BR
}

\begin{abstract}
RESUMO: Atualmente, o debate sobre a formação do português brasileiro (PB) encontra-se dividido entre duas hipóteses que podem ser definidas como hipótese externalista (crioulista) e hipótese internalista (derivista). A hipótese externalista sugere que os aspectos distintivos do $\mathrm{PB}$ decorrem de um processo de crioulização prévio motivado pelo contato massivo com línguas africanas no período da escravidão. A hipótese internalista, embora não ignore o contato de línguas na formação do PB, afirma que tal contato não foi determinante para o surgimento das suas características distintivas e sugere que essas características remetem a possibilidades estruturais já inscritas na deriva da língua. Este ensaio traz uma breve análise dos fatos linguísticos usualmente invocados pela hipótese externalista e apresenta um novo argumento à hipótese internalista a partir do conceito de settling, proposto por Seuren (2013). Este novo argumento aponta para as consequências da língua-geral que se formou no início da colonização brasileira, a partir da fusão dos distintos dialetos falados pelos imigrantes portugueses, e vincula esta língua-geral ao fato de o PB ser, ao mesmo tempo, altamente conservador e inovador.
\end{abstract}

PALAVRAS-CHAVE: formação do português brasileiro; crioulização; deriva linguística.

RESUMEN: Actualmente, el debate acerca de la formación del portugués brasileño (PB) se encuentra dividido entre dos hipótesis que pueden ser definidas como hipótesis externalista (criollista) e hipótesis internalista (derivista). La hipótesis externalista sugiere que los aspectos distintivos del PB resultan de un proceso de criollización previo motivado por el contacto masivo con lenguas africanas en el período de la esclavitud. La hipótesis internalista, aunque no ignore el contacto de lenguas en la formación del PB, afirma que tal contacto no fue determinante para el surgimiento de sus características distintivas y sugiere que esas características remiten a posibilidades estructurales ya inscriptas en la deriva de la lengua. Este ensayo trae un breve análisis de los hechos lingüísticos usualmente invocados por la hipótesis externalista y presenta un nuevo argumento a la hipótesis internalista a partir del concepto de settling, propuesto por Seuren (2013). Este nuevo argumento indica para las consecuencias de la lengua-general que se formó en el comienzo de la colonización brasileña, a partir de la fusión de los distintos dialectos hablados por los inmigrantes portugueses, y vincula esta lengua-general al hecho del PB ser, a la vez, altamente conservador e innovador.

PALABRAS-CLAVE: formación del portugués brasileño; criollización; deriva lingüística.

ABSTRACT: Nowadays, the debate on Brazilian Portuguese (PB) formation is divided between two hypotheses that it can be defined as externalist hypothesis (creolist) and internalist hypothesis (drift). The externalist hypothesis suggests that the distinctive aspects of $\mathrm{PB}$ result from a process of creolization motivated by the massive contact with African languages in the slavery period. The internalist hypothesis, though it doesn't ignore the languages contact in the formation of PB, states that such contact wasn't determinant to develop its distinctive features and suggests that these features refer to structural possibilities inscribed in its drift. This essay presents a brief analysis of the linguistic facts usually invoked by externalist hypothesis and presents a new argument to the internalist hypothesis from the concept of settling, proposed by Seuren (2013). This new argument points to the consequences of the general language formed in the early colonization of Brazil, from the merger of different dialects spoken by Portuguese immigrants, and binds this general language to the fact that PB is at the same time highly conservative and innovative.

KEYWORDS: Brazilian Portuguese formation; creolization; linguistic drift.

\section{INTRODUÇÃO}

A formação do português brasileiro (PB) é um debate aberto, no qual ainda há muito por explorar. Até hoje, surgiram três hipóteses que tentaram explicar por que a principal língua falada no Brasil difere significativamente do português europeu (PE). A primeira hipótese, o chamado biologismo linguístico, caiu na obsolescência no início do século XX. As outras duas, cujos adeptos ainda se debatem, podem ser definidas como hipótese externalista (crioulista) e hipótese internalista (derivista).

A hipótese externalista sugere que os aspectos distintivos do PB decorrem de um processo de crioulização prévio motivado pelo contato massivo com línguas africanas no período da escravidão. A hipótese

*Email: luizqueriquelli@yahoo.com.br. 
internalista, embora não ignore o contato de línguas na formação do $\mathrm{PB}$, afirma que tal contato não foi determinante para o surgimento das suas características distintivas e sugere que essas características remetem a possibilidades estruturais já inscritas na deriva da língua.

Neste ensaio, pretendo analisar os fatos linguísticos do PB usualmente invocados pela hipótese externalista e acrescentar um novo argumento à hipótese internalista a partir do conceito de settling, proposto por Seuren (2013). Em linhas gerais, a novidade que pretendo trazer ao debate baseia-se em duas questões interconectadas, que acredito ainda não terem sido devidamente consideradas: Quais as consequências da língua-geral que se formou no início da colonização brasileira a partir da fusão dos distintos dialetos falados pelos imigrantes portugueses? Essa língua-geral tem alguma relação com o fato de o PB ser, ao mesmo tempo, altamente conservador e inovador?

Tais questões serão consideradas no último tópico deste ensaio. Antes, porém, comentarei a hipótese biologista e traçarei um panorama do debate atual entre os externalistas e os internalistas.

\title{
2 BIOLOGISMO LINGUÍSTICO
}

A perspectiva conhecida como biologismo linguístico ou hipótese evolucionista ganhou adeptos no século XIX, no auge do Romantismo, quando a teoria evolucionista de Darwin era a sensação do meio científico. Aqueles que ficaram conhecidos como biologistas linguísticos tentaram aplicar os pressupostos darwinianos à linguagem a fim de explicar a formação do PB. Eles consideravam que as línguas evoluíam como organismos biológicos e, movidos por um ímpeto nacionalista e ufanista, acreditavam ser o PB a evolução do PE, assim como o PE teria sido a evolução do latim vulgar (CASTILHO, 1999). O escritor Monteiro Lobato (1938 apud MELLO, 1971, p. 19), a propósito, chegou a afirmar: "Assim como o português saiu do latim, pela corrupção popular desta língua, o brasileiro está saindo do português. O processo formador é o mesmo: corrupção da língua-mãe. A cândida ingenuidade dos gramáticos chama corromper ao que os biologistas chamam evoluir".

Entretanto, logo, muitos ataques a essa corrente mostraram que a língua não é um fato biológico, mas um fato social, sujeito também a arbitrariedades humanas e não apenas ao determinismo da natureza. Até mesmo William Whitney - eminente defensor do positivismo linguístico, autor de Darwinismo e Linguagem, uma das principais inspirações dos biologistas - asseverou:

\begin{abstract}
[...] a linguagem não é um feito natural, uma propriedade biológica, mas um fato social. É preciso reconhecer a sociedade como árbitro soberano pelo qual se decide a questão de saber se uma inovação passará à língua. É preciso que alguém comece: se não o seguem, está abortada (WHITNEY, 1867 apud CASTILHO, 1999, p. 242).
\end{abstract}

Ao dizer que a linguagem não é um feito natural, acredito que Whitney estivesse sugerindo que as línguas não evoluem da mesma maneira que organismos biológicos. Neste caso, para ser mais preciso, talvez seria mais apropriado referir-se a fato biológico ao invés de "feito natural". Contudo, como nota CASTILHO (1999), Whitney antecipou muitas afirmações da atual sociolinguística ao sugerir que

[...] do trabalho imperceptível de alteração da língua, realizado pelos falantes, cujo conjunto lentamente modifica o todo, decorrem variações de ordem geográfica e social, estas diretamente associadas à profissão, grau de educação, idade e classe social (WHITNEY, 1867 apud CASTILHO, 1999, p. 242).

É possível afirmar também que o biologismo linguístico tem paralelos com uma visão materialista predominante na filosofia da linguagem até o século XIX, a qual incluía a língua no plano da realidade material. Seuren (2013), cujo conceito de settling ainda invocarei, critica essa visão. Em seu entendimento, podemos distinguir três realidades: a realidade material (o plano das coisas físicas), a realidade virtual (onde projetamos nossas ações, sem necessariamente realizá-las) e a realidade social (o plano daquilo que só existe mediante as relações entre as pessoas). A despeito de aspectos fonéticos ${ }^{1}$, Seuren (2013) defende que a língua pertence à realidade social, pois não existiria se as pessoas não se relacionassem entre si. Este argumento, em certa medida, também depõe contra o biologismo linguístico.

1 A língua se realiza no som, e o som é matéria. Portanto, aspectos fonéticos poderiam ser invocados para argumentar a favor da visão materialista da linguagem. 
No início do século XX, assim como muitas outras tentativas de aplicar os pressupostos darwinianos em outros campos científicos, o biologismo linguístico fracassou na pretensão de explicar a formação do PB. Uma vez que essa hipótese caiu na obsolescência, pouco a pouco, isoladamente, às vezes separados por décadas de silêncio acadêmico, surgiram novos argumentos que hoje são organizados na dicotomia "hipótese externalista (crioulista) versus hipótese internalista (derivista)".

\section{PANORAMA DO DEBATE ATUAL}

Os externalistas afirmam que as diferenças do PB em relação ao PE decorrem do contato entre línguas (português e línguas africanas em especial ${ }^{2}$ ) havido na fase de colonização do Brasil, isto é, decorrem de fatores externos à estrutura autônoma da língua. Mais especificamente, Pessoa de Castro (1967), Holm (1987), Baxter (1992), Lucchesi (1994, 2009), entre outros, sugerem que houve um processo de crioulização no Brasil colonial que fez surgir as características distintivas do PB, ou seja, em certo momento devem ter existido pidgins, misto de português e línguas faladas por escravos africanos, e tais pidgins foram nativizados por crianças, dando origem a crioulos de português. Esses crioulos de português vieram a desaparecer posteriormente, porém antes de desaparecer legaram características à língua popularmente falada no Brasil, e tal legado determinou a identidade dessa língua, distinguindo-a do português europeu padrão.

Os internalistas, embora não ignorem a agência de outras línguas na formação do PB, tentam mostrar que suas características particulares (ou suas diferenças em relação ao PE) respeitam fatores internos, estruturais; isto é, seguem tendências que a própria língua já insinuava antes mesmo de cruzar o Atlântico. Mcworther (1999), Parkvall e López (2003), Scherre e Naro (2007), Noll (2008), entre outros, cada qual ao seu modo, têm buscado provar que, apesar de tudo contribuir a favor, não há nada no PB que possa ser considerado resultado necessário de crioulização prévia; no máximo, seria possível admitir que certas tendências do português foram aceleradas ou catalisadas com o contato de línguas.

Ainda que nem todos os internalistas admitam esta associação, Scherre e Naro (2007) vinculam os trabalhos de cunho internalista à teoria da deriva linguística (linguistic drift) ${ }^{3}$. A noção de deriva linguística surgiu com Edward Sapir, que em uma de suas principais obras fez as seguintes observações:

[...] a língua se move ao longo do tempo num curso que lhe é próprio. Tem uma deriva. [...] Embora não percebamos, nossa língua tem uma inclinação […], as mudanças dos próximos séculos estão em certo sentido prefiguradas em certas tendências não perceptíveis no presente (SAPIR, 1921, p. 150-155 apud SCHERRE; NARO, 2007, p. 26).

Tal percepção de Sapir veio a ser endossada pela linguística sócio-histórica nas décadas seguintes. Enquanto trabalhos de diversos sociolinguistas no Brasil evidenciaram uma série de mudanças em curso no $\mathrm{PB}$, linguistas históricos mostraram que muitas dessas mudanças possuem precedentes ou são paralelas a fenômenos já existentes no português arcaico, no romance ibérico e no latim. Em 1994, William Labov, fundador da linguística variacionista, explicitou um princípio que, até então, era apenas inferível de suas formulações teóricas: o princípio uniformitarista, segundo o qual "o conhecimento dos processos que operaram no passado [de uma língua] pode ser inferido pela observação dos processos em andamento no presente" (LABOV, 1994, p. 21). Isso deu novo impulso para os adeptos da hipótese internalista e trouxe de volta ao debate um argumento antigo, lançado no início da década de 50 por Serafim da Silva Neto.

Silva Neto (1950), pioneiro nos estudos de dialetologia no Brasil, defendeu em seus escritos a tese do conservadorismo ou caráter arcaizante do português que se formou neste país. Quando falava em conservadorismo, no entanto, não fazia nenhuma abordagem moral da questão. Pretendia estritamente defender a ideia de que a nossa língua, de modo predominante, conserva características do chamado

\footnotetext{
2 Embora os defensores dessa hipótese, como Lucchesi, Baxter e Ribeiro (2009), admitam a influência de línguas indígenas e outras línguas europeias também trazidas ao Brasil, seus argumentos sempre apontam para a influência de línguas africanas, principalmente as línguas nagô, congo e benguela.

3 Theo Vennemann, em "An explanation of drift” (1975), faz uma grande revisão da teoria da deriva. Ele revisita os pressupostos de Sapir (1921) e mostra que podem ser inscritos nessa mesma corrente trabalhos posteriores de uma série de autores, entre eles Ch. C. Fries, Lakoff, Greenberg e Lehmann. Nem todos esses autores vincularam seus trabalhos à teoria da deriva, porém Vennemann mostra que a ligação deles com a proposta de Sapir é evidente. O mesmo parecem fazer Scherre e Naro (2007) em relação aos autores que adotam uma perspectiva internalista para explicar a formação do PB.
} 
português arcaico (PA) - a língua que chegou à América, formada entre os séculos XIII e XV - enquanto que o português europeu, de modo predominante, ao longo de sua formação, inova as características daquela língua. Como pontua Noll (2008, p. 277), "arcaicidade e inovação são categorias neutras, dependentes de uma variedade de referência que se orienta por alguma norma linguística”.

Um fato que corrobora o argumento conservadorista é a estagnação de diversas tendências que não só o PB apresentou, mas também o castelhano das diversas colônias espanholas da América Latina desde que atravessou o Atlântico. O português e o castelhano foram transplantados para a América; aqui, em um contexto completamente novo e radicalmente diferente, as mudanças que vinham ocorrendo em ambas as línguas havia séculos em solo europeu tiveram de estacionar para que a língua se adaptasse às novas condições. Silva Neto (1950, p. 188) fala em isolamento cultural, desengranzamento de sincronias, ossificação do idioma e fratura na transmissão linguística:

Tais áreas arcaizantes estão muito afastadas dos grandes centros, já por causa de obstáculos naturais: um rio, uma cadeia de montanhas, já por falta de comunicações. Há lugares que nunca viram um automóvel! Portanto o isolamento facilitou a estagnação da língua, mantendo-se, pelo Brasil adentro, verdadeiras ilhas culturais. Algumas têm, até, caráter especialíssimo, extra-romântico. [...] Confirma-se, pois, o princípio de que as áreas mais isoladas são mais arcaicas. [...] A língua é uma sucessão de fases, de continuidades: cada fase é resultante das anteriores. Ora, viajando para o Brasil, o português foi desarraigado. Provocou-se, desse modo, um desengranzamento de sincronias, do que resultou a ossificação do idioma. Houve, em suma, uma fratura na transmissão linguística. Essa fratura foi menor no litoral e muito maior no interior.

Do ponto de vista social, isso é bastante compreensível. Certamente - e a documentação migratória comprova isso - não foi apenas uma comunidade linguística que chegou ao Brasil, por exemplo, mas sim várias e distintas comunidades, com diferentes falares ${ }^{4}$. Uma vez postos em contato, sem que pudessem usar seus dialetos naturalmente, aqueles aloglotas em solo brasileiro tiveram de buscar um denominador comum para que se entendessem mutuamente. Essa língua comum construída no Brasil, até se estabelecer e alcançar gerações de falantes, de alguma forma arrefeceu e teve sua evolução retardada em relação à língua que continuou seu curso normal na Europa.

Tal busca por um código comum entre aloglotas portugueses que povoaram o Brasil pode estar diretamente relacionada ao processo de settling do português brasileiro, argumento que colocarei e desenvolverei no tópico 4, mais adiante. Antes, contudo, julgo necessário discutir alguns problemas epistemológicos de ambos os lados desse debate.

\section{PROBLEMAS EPISTEMOLÓgICOS}

Tanto a hipótese crioulista quanto a derivista, porque são cabíveis, ainda se encontram vivas no debate e têm sido igualmente exploradas. Entretanto, as versões fortes de ambas têm problemas epistemológicos. Grosso modo, é possível dizer que a versão forte da teoria crioulista afirma que necessariamente as diferenças do PB decorrem de um processo de crioulização (tendo o português como superstrato e principalmente línguas africanas como substrato). A condição necessária dessa hipótese, como tentarei mostrar, é quebrada quando se verifica que todos os fenômenos supostamente resultantes da ação de línguas africanas na formação do PB alegados por HOLM (1987), por exemplo, existem de modo idêntico em muitas outras línguas, latinas e não latinas, que jamais tiveram, em seu processo de formação, contato massivo com alguma língua africana, como é o caso do sueco:

O sueco (idioma que escolhemos simplesmente por ser esta a primeira língua de um dos autores, mas poderíamos chegar às mesmas conclusões utilizando muitas outras línguas) é uma língua que não passou por formas extremas de contato linguístico. Durante os últimos 800 anos, os seus falantes reduziram o sistema de gênero de três a dois gêneros gramaticais, deixaram de usar as flexões de caso para o acusativo e o dativo, abandonaram totalmente os paradigmas do subjuntivo e do condicional, deixaram

\footnotetext{
4. Silva Neto (1979 [1952], p. 581-587), em um estudo sobre a origem dos colonizadores do Brasil, mostra que, embora a tradição sempre tenha afirmado que a maior parte dos colonizadores vieram do sul de Portugal, a documentação migratória mostra a procedência foi bastante heterogênea e não houve de fato nenhum predomínio dos sulistas. Entretanto, o autor admite que “[ [...] embora a teoria do predomínio da gente do sul na colonização não pareça corresponder à verdade, não se pode negar que, em geral, afinal tanto o português do Brasil como o espanhol americano apresentam numerosas semelhanças com a língua falada nas zonas meridionais”. Retomarei este ponto no tópico 4.
} 
de marcar a concordância de pessoa e número nos verbos (isso fez com que o número de formas nos paradigmas que restam tenha sido reduzido de seis a um). A ordem das palavras estabilizou-se como SVO com V2, substituindo a ordem anterior que era SOV, e os pronomes de sujeito tornaram-se obrigatórios. $\mathrm{Na}$ fonologia, as fricativas interdentais $/ \theta$, ठ/ foram substituídas pelas equivalentes dentais /t, d/, e constatamos a palatalização das implosivas que precedem as vogais altas anteriores, à semelhança do PVB [português vernáculo brasileiro]. Alguns dialetos abandonaram as vogais anteriores arredondadas. O processo levou aproximadamente três séculos mais do que o período de formação do PVB, mas as reduções não são menos radicais do que as apresentadas na maioria das variantes do PVB. Sem dúvida, ninguém afirmaria que este é um fato a ser considerado como "provas abundantes” para demonstrar que o sueco é descendente do são-tomense. O sueco não é uma língua de contato e, portanto, nunca poderia ser classificado na mesma categoria que os semi-crioulos, nem mesmo pelos mais fervorosos defensores de uma hipótese de semi-crioulizacjao no Brasil (PARKWALL; LÓPEZ, 2003, p. 133).

Segundo Lucchesi e Lobo (1996), as principais características sintáticas que diferenciam o português vernáculo brasileiro da modalidade europeia da língua portuguesa seriam as seguintes:

1) realização do sujeito lexical e redução na flexão número-pessoal do verbo (EU vejo / NÓS fala (mos));

2) variação da concordância nominal com preferência pela marcação do plural apenas no primeiro elemento do $\mathrm{SN}(\mathrm{OS} \operatorname{carro}(s) / A S \operatorname{casa}(s))$;

3) realização variável do objeto direto, ou clíticos acusativos de $3^{\mathrm{a}}$ pessoa, com as variáveis objeto nulo/forma nominativa da $3^{\mathrm{a}}$ pessoa (Eu vejo/Eu vejo ELE);

4) colocação dos clíticos em posição pré-verbal (ME diga uma coisa);

5) estratégias de relativização: relativa com lacuna/relativa com pronome lembrete ${ }^{5} /$ relativa $^{2}$ cortadora (eu tenho uma professora que [Q] é sueca/eu tenho uma professora que ELA é sueca/a professora que eu falei com ELA ontem/a professora que eu falei [Q] ontem);

6) ordem dos constituintes na oração é SVO e possibilidade de interrogativas-Q sem nenhum movimento (eu como acarajé/você mora onde?);

7) preferência do falante brasileiro pelas formas do gerúndio quando o português escolhe a forma [a + infinitivo] (estou falando).

$\mathrm{Na}$ tese crioulista, essas características teriam sido induzidas pelo contato com línguas africanas ou teriam sido legadas por crioulos que surgiram no período da colonização, mistos de português com línguas africanas, isto é, seriam resultado de um processo de crioulização prévio. Tentarei analisar cada característica caso a caso.

Baxter (2009) afirma que as características 1 e 2 foram induzidas no PB por escravos que vieram ao Brasil e falavam o são-tomense, uma língua crioula de base portuguesa, cujo substrato assenta principalmente nas línguas kwa, faladas na Costa do Marfim, Gana, Togo, Benim e Nigéria. Baxter (2009, p. 270) baseia o seu argumento comparando exemplos de fala de uma comunidade quilombola do interior do Estado da Bahia, no Brasil, chamada Helvécia, e de uma comunidade de São Tomé, na África, chamada Monte Café. Eis uma de suas comparações:

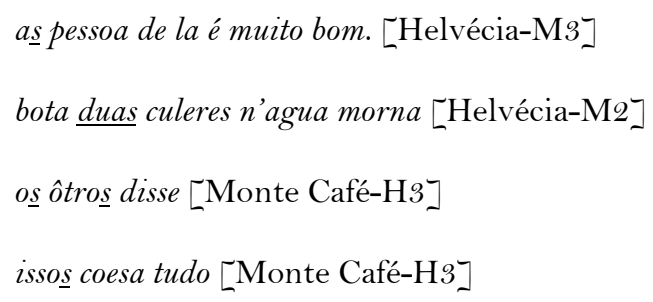

Essa característica poderia, sim, ter sido induzida no PB por escravos falantes do são-tomense, entretanto, por que afirmar que essa indução é algo necessário? Diversas outras línguas, românicas e não românicas,

\footnotetext{
5 Esse tipo de relativização também é chamado de "relativização com pronome ressuntivo". "Que" já não é mais considerado um pronome relativo mas uma partícula relativa; no exemplo, "ela" consiste em um pronome ressuntivo. A propósito, esta construção é padrão no idioma árabe.
} 
que não sofreram processos de crioulização, já passaram pelo mesmo processo, em geral por conta de erosões fonéticas que motivaram mudanças no paradigma morfossintático: o inglês e o francês são exemplos clássicos. Além disso, encontramos esse mesmo fenômeno em Portugal; Scherre e Naro (1999, p. 235) fornecem os seguintes exemplos:

$$
\begin{aligned}
& \text { era duas, três sardinha } \\
& \text { eu onte foi à Malhada }
\end{aligned}
$$

Não só encontramos exemplos hoje em dia em Portugal, como também tal fenômeno já se manifestava no português arcaico (PA). Joseph Huber, filólogo alemão autor de Altportugiesisches Elementarbuch (Gramática do Português Antigo), publicada originalmente em 1933, notou alguns casos correntes no PA em que ocorria variação de concordância entre sujeito e predicado. Huber (1986 [1933], p. 152-154) faz os seguintes comentários a cada um desses casos.

443. nẽ hũa cousa ('nada') é tratado como masculino: Nom lhes foi revelado nẽ hũa (Euf. 362). Nom foi a nos demonstrado nẽhũa cousa (Euf. 362).

Também gentes se liga por vezes, no sentido de homens, a um predicado masculino: Muytas hi há de gentes... que som avyados a perdiçon (TA. 50).

444. Quando de dois sujeitos um é masculino e o outro feminino, o predicado encontra-se na forma masculina: A alma e o corpo ... foram ajuntados em hũu (Corte imperial, p. 215 segundo Dias, Syntaxe, p. 16). As suas mãaos e os seus braços eram muy delleitosos pera veer (da Corte imperial em TA. 61).

445. Quando de dois sujeitos um está na $1 .^{a}$ pessoa e o outro na $2 .^{\mathrm{a}}$ ou $3 .^{\mathrm{a}}$ pessoa do sing., o respectivo predicado encontra-se na 1. a pessoa do plural: Padeçemos vós e eu (CG. III, 75). Si eu e a raina formos mortos, ... (1214).

446. Por vezes, apesar de existirem dois sujeitos, o predicado encontra-se no singular: E per esta guisa morreo o lobo e a rraposa (Fab. 32).

Isto verifica-se especialmente quando os sujeitos são sinônimos: A emjuria e vergonça nom he d'aquell que a rrecbe, mays He d'aquelle que a faz (Fab. 18). Muyta foi a alegria e folgança (TA. 95). Note-se em ambos os casos a omissão do artigo definido no segundo sujeito.

Nota: Para hi ha ou $i a ́(=$ fr. il y a) pode aparecer um sujeito no singular ou no plural: outros $i a ́$; muytas hi ha de gentes, cf. $\S 443$.

447. Quando o sujeito apresenta uma forma de singular, mas tem significação de plural, o predicado encontra-se no plural: $E$ logo ... se ajuntarom deante Santo Antonio tamanha multidom de pexes grandes $e$ pequenos (Milagres de Sto. Antonio 1). - toda a cristãidade que estã ẽ grã coyta (Nunes 49).

É interessante o seguinte exemplo pelo fato de o predicado para o mesmo sujeito (gente) aparecer uma vez no singular e outra no plural: Toda gemte te lança de ssy com nojo de que de ty han (Fab. 23); cf. Leite de Vasconcellos, O livro de Esopo, 1906, pág. 111.

448. Mais raro é encontrar-se o predicado no singular quando o sujeito vem no plural: $E$ hi morreo grandes gentes (Nunes 52). Contudo isto parece apenas verificar-se quando o predicado antecede o sujeito.

Os casos relatados nos parágrafos 444 e 445 são previstos mesmo nas atuais gramáticas europeias e, embora tenham causado estranheza a Huber, são irrelevantes no momento. $\mathrm{O}$ caso 445, a propósito, diz respeito à conhecida distinção entre a $1^{a}$ pessoa do plural inclusiva ("eu e você") e a exclusiva ("eu e os outros"), encontrada em muitas línguas do mundo, embora ainda não esteja claro por que todas essas línguas assumem a forma da $1^{\mathrm{a}}$ do plural, e não as formas inclusivas da $2^{\mathrm{a}}$ e $3^{\mathrm{a}}$ pessoa do plural respectivamente. Entretanto, os casos expostos nos parágrafos 443, 446, 447 e 448 são variações de concordância comparáveis às trazidas por Baxter. Scherre e Naro (2007, p. 153) trazem outros exemplos de variação de concordância no português arcaico:

1) mas DAVA ( $3^{\mathrm{a}} \mathrm{sg}$.) lhe gram torva as portas çarradas Vida e Feitos de Júlio César, p. 224, cxxxix 
2) a todos aqueles que se fazem ( $3^{\mathrm{a}} \mathrm{pl}$.) afora da carreira do pecado e TORNA ( $3^{\mathrm{a}} \mathrm{sg}$.) a dereita carreira $\mathrm{A}$ Demanda do Santo Graal, xxi, 160, p. 223

3) Entom os parentes OUVE ( $3^{\mathrm{a}} \mathrm{sg}$.) conselho e confessaron ( $3^{\mathrm{a}} \mathrm{pl}$.) Os Diálogos de São Gregório, $1.24 .23(35)$

4) Aqueles que, da gente d'Alexandria, REINOU ( $\left.3^{\text {a }} \mathrm{sg}.\right)$ no Egipto. Vida e Feitos de Júlio César, p. $554,1.12$

Diante de tudo isso, por que afirmar que o PB herdou do são-tomense essa característica, uma vez que ela já existia nos dialetos dos falantes portugueses que povoaram o Brasil? Esses fatos parecem quebrar a versão forte da tese crioulista.

O mesmo vale para as características 3 e 4, que Lucchesi e Mendes (2009) afirmam ser resultado de crioulização prévia no PB, por enxergarem semelhanças com o crioulo de Cabo Verde. A preferência que o PB apresenta pela próclise (característica 4) é a tendência geral de todas as línguas românicas e já existia no PA. A próclise do pronome átono é corrente no PB até mesmo em enunciados em que, categoricamente no $\mathrm{PE}$, a ênclise é exigida. Essa questão é muito debatida desde o século XIX e, atualmente, é rotulada de "posição dos clíticos". Na literatura crioulística internacional, é consenso que cliticização não tem nada a ver com crioulização.

A este respeito, ainda cabe notar que Mattos e Silva (2004), embora não se declare favorável ao argumento do conservadorismo, reconhece que o plano sintático apresenta de fato muitos traços conservadores. Segundo ela, "[...] no século XVI, os clíticos se tornaram mais proclíticos na documentação quinhentista que na arcaica e, no correr da história do português europeu, a ênclise voltaria a ser privilegiada" (p. 136). Considerando que, justamente nessa época em que a língua se tornou proclítica, o Brasil recebeu um grande influxo de colonizadores, tal tendência trazida pode ter se perpetuado aqui, enquanto que lá foi dirimida ao menos na variedade padrão.

A tendência proclítica, porém, já se fazia presente de modo significante desde o início do período arcaico. Eidelwein (2010) analisou uma série de textos desse período, entre eles, crônicas de Roi Fernández de Santiago e Fernão Lopes, poemas de Afonso Sanches, Joan Soares Coelho, Lopo Lias e João Garcia de Guilhade, uma cantiga de Dom Dinis, um relato chamado "A Notícia do Torto" e um documento oficial chamado "Carta dos Juízes de Abrantes". A partir de sua análise, o autor constatou o seguinte.

\begin{abstract}
[...] a próclise é utilizada em muitas situações em que hoje, a ênclise seria utilizada em Portugal, incluindo em posição inicial de oração. Se constata, por conseguinte, a flexibilização das colocações pronominais mesmo nesse período que foi, segundo Teyssier, o período de fixação da ênclise em Portugal. (EIDELWEIN, 2010, p. 30).
\end{abstract}

Essa constatação reforça a tese de que o PA era flexível em muitos aspectos sintáticos assim como o PB ainda o é. Resumindo a linha argumentativa, podemos sugerir o seguinte: a posição dos clíticos era variável no PA; no início do período arcaico, predominava a ênclise, porém na passagem para o período moderno houve uma emergência da próclise; o PE dirimiu a tendência proclítica e normatizou a ênclise, enquanto que o PB conservou a flexibilidade clítica do PA, salientando a tendência proclítica trazida no século XVI ao Brasil.

Além disso, para a característica 3 - realização variável do objeto direto, ou clíticos acusativos de $3^{\text {a }}$ pessoa, com as variáveis objeto nulo/forma nominativa da $3^{\text {a }}$ pessoa $(E u$ vejo/Eu vejo $E L E)$ - existe uma explicação estrutural bastante plausível. Mattoso Câmara Jr. (1957 apud CASTILHO, 1999, p. 243), que já estudou a fundo a hipótese crioulista, defende a seguinte explicação para o fenômeno em questão:

Partindo do pressuposto de que a colocação pronominal brasileira é predominantemente proclítica, visto que nessa variedade não há pronomes oblíquos propriamente átonos, [...] a anteposição de $o, a$ ao verbo (como em $o \mathrm{vl}$ ) formaria um vocábulo fonético iniciado por vogal, situação em que se manifesta a tendência à aférese dessa vogal (como em magina por imagina etc.). Ora, no nível sintático, essa vogal desempenha o papel de argumento do verbo, e assim sua perda acarretaria um prejuízo na organização da oração. Vem daqui sua substituição por ele, que se transforma na estrutura do PB numa forma invariável, apta a desempenhar a função de nominativo ou de acusativo. Não é necessário, portanto, recorrer à influência de falares crioulos para justificar essa construção, como fizeram diversos autores. 
Com respeito às características 5 e 6 , que se referem a estratégias de relativização, ordem dos constituintes SVO e possibilidade de interrogativas-Q sem nenhum movimento, é importante notar - conforme os próprios crioulistas admitem - que "[ $[\ldots]$ do ponto de vista empírico, o estudo das sentenças relativas nessas comunidades [quilombolas] não fornece evidências de um processo anterior de pidginização/crioulização do PB" (RIBEIRO, 2009, p. 185). Quanto à ordem dos constituintes, devemos notar que a ordem SVO já havia se estabelecido desde o latim vulgar, porquanto não há necessidade de afirmar que se trata de uma característica crioula. As estratégias de relativização, assim como as sentenças interrogativas sem movimento, são reconhecidamente uma inovação do PB e têm sido exaustivamente estudadas. Uma excelente revisão desse assunto foi feita recentemente por Almeida e Lima-Salles (2011). Quanto às estratégias de relativização, parece claro que se trata de um caso de "reanálise" da estrutura gramatical, porém as motivações dessa reanálise não são plenamente conhecidas. As interrogativas sem movimento indicam que o PB comporta-se como uma língua de tópico-comentário, sendo que as relações de restrição e escopo são indicadas pela saliência fônica na frase.

Quanto à característica 7 (a preferência pelo gerúndio ao invés do infinitivo preposicionado em perífrases), mais uma vez podemos encontrar a mesma forma no português arcaico. Como admitem Cunha (1986) e Paiva Boléo (1974), a construção estar (andar etc.) + gerúndio, preferida no Brasil, é a mais antiga no idioma (em comparação com o infinitivo preposicionado) e ainda tem vitalidade em dialetos centro-meridionais de Portugal (principalmente no Alentejo e no Algarve), nos Açores e nos países africanos de língua oficial portuguesa. "Os escritores portugueses e brasileiros contemporâneos preferem, obviamente, a construção predominante em seus respectivos países, mas servem-se supletivamente da outra" (CUNHA, 1986, p. 221).

Mattos e Silva (2004), que questiona também esse ponto, lembra que esse fato sintático foi estudado pelo filólogo sueco Bertil Maler, em 1972, que analisou textos poéticos e teatrais do século XVI e verificou que essa variação já acontecia então. Para a autora, isso muda um pouco a questão: se ambas as perífrases eram possíveis no PA, alguma delas era mais regular? Qual surgiu primeiro?

Respondendo - não de modo definitivo - a esses questionamentos, cabe observar que, além de Cunha, Boléo e outros especialistas insistirem em afirmar que estar + gerúndio é a construção mais antiga (em comparação com o infinitivo preposicionado), é significativo o fato de Huber (1986 [1933]), em sua Gramática do Português Antigo (baseada em textos que vão desde os primórdios do PA, no século XII, até o século XV), não ter feito nenhuma menção à construção estar + a + infinito (típica do PE) e, por outro lado, ter dado destaque à perífrase que utiliza o gerúndio, atestando sua normalidade.

367. andar, ir, ser ou ficar + gerúndio usam-se muitas vezes para formar a linguagem perifrástica do verbo simples:

a) Paununcio andava catando algũu homẽ santo (Euf. 357). Sempre andou buscando os hermos (TA. 64). Seu abade Sam Bẽento ho amoestou muytas vegadas que nõ andasse vaguejando pelo mundo (TA. 45). A aguia, andando buscando caça pera seus filhos, achou os filhos da raposa (Fab. 13).

b) Pela ribeira do rio cantando ía la dona-virgo (CV. 767). Foi correndo ao abade (Euf. 365). Eu mui passo fui-mi achegando (CV. 454). Foi (fui) poderia também ser pret. perf. definido de seer 'ser', cf. $\S 401,5$.

c) Seve chorando CD. 1660. Seve jurando CD. 1661. Quanto a seve, cf. $\$ 404,2$.

d) Per esta guisa o leom ficou chorando (Fab. 16).

368. estar + gerúndio designa uma acção que está precisamente a decorrer num certo momento e ainda não terminou; por exemplo: Está a aquella freesta fallando com Dom Galvam (Graal 1). - Ela s'estava queixando (CD. 448). - estar comendo (Fab. 12). (HUBER, 1986 [1933], p. 211).

Esses fatos sugerem que, se a perífrase com o gerúndio não é a forma mais antiga para expressar o aspecto de continuidade, foi ao menos a forma mais regular no PA. Consequentemente, faz sentido afirmar que o PB é mais conservador por ter mantido essa construção, enquanto que o PE fez emergir a perífrase com o infinitivo preposicionado. Portanto, mais uma vez, não é preciso invocar a hipótese de crioulização prévia para explicar essa característica. Ademais, estes fenômenos não podem estar relacionados a crioulização, uma vez que não existe nada semelhante em nenhum dos possíveis substratos africanos. 
Diante desses fatos, considerando a insuficiência de indícios de crioulização na gramática do PB, Parkvall e López (2003, p. 114) afirmaram:

[...] enquanto a distância entre o PVB [português vernacular brasileiro], inclusive as variantes rurais que mais se afastam do padrão, e o português europeu padrão é constituída por um conjunto limitado de características, a distância entre o primeiro e um crioulo prototípico é considerável.

O filólogo e dialetologista alemão Volker Noll (2008, p. 290), tendo examinado e comparado as pesquisas ligadas a esse debate, afirmou:

As teses de influências externas específicas no desenvolvimento do português brasileiro não são verificáveis. Isso vale, de igual modo, para a influência africana, no sentido de uma antiga crioulização [...], para as influências indígenas ou africanas fora do vocabulário [...], para a suposta predominância das variedades meridionais do português europeu na formação do português brasileiro [...], para a alegada influência da Corte portuguesa na difusão do chiamento no Rio de Janeiro [...] e para a assumida influência açoriana em Santa Catarina.

Isso sugere que tais fenômenos estão ligados a universais linguísticos ou, ainda, que fazem parte da deriva de uma série de línguas afins. Nesse ponto, porém, essa segunda hipótese - embora atraente - começa a ficar etérea e impalpável, o que dificulta testes de falseamento e, logo, sua verificação científica. Eis o ponto falho da versão forte da teoria da deriva: o que é exatamente a deriva de uma língua? Como enxergar a deriva e submetê-la a uma apreciação objetiva se até mesmo Sapir, autor do conceito, afirmou que as inclinações de uma língua e as mudanças pelas quais ela passará no futuro são imperceptíveis no presente?

Vennemann (1975), para tentar minimizar a vagueza do conceito de deriva, revisitou os pressupostos de Sapir e mostrou que podem ser inscritos nessa mesma corrente trabalhos posteriores de uma série de autores, entre eles Ch. C. Gries, Lakoff, Greenberg e Lehmann. Nem todos esses autores vincularam seus trabalhos à teoria da deriva, porém Vennemann mostra que a ligação deles com a proposta de Sapir é evidente. Nesse mesmo ensaio, Vennemann tenta - e em certa medida consegue - reconstruir as transformações estruturais que levaram línguas sintéticas como o latim, o grego e o proto-germânico, cuja ordem dos constituintes era SOV, a se transformarem em línguas analíticas, com predominância da ordem SVO. No Brasil, tendo em conta a formação do PB, a primeira aplicação da teoria da deriva foi levada a cabo pelo já citado Câmara Jr. em 1957. Muitos outros trabalhos se seguiram a este, com destaque para Naro (1971), que focalizou mudanças fonético-fonológicas, e Scherre e Naro (2007), que acrescentaram mudanças sintáticas aos estudos derivistas.

Todos estes estudos citados de alguma forma contribuem para viabilizar a apreciação de uma deriva linguística e para torná-la mais palpável. Podemos não dispor de muitos recursos para prever os caminhos que uma língua percorrerá, mas podemos tentar recuperar os caminhos que ela já percorreu e tirar conclusões minimamente seguras disso. Portanto, parece-me que, para tentar encontrar uma resposta para o que é a deriva, a linguística histórica, a filologia e outras abordagens diacrônicas se apresentam como alternativas cabíveis, ainda que potencialmente fracas diante da imensidão de dados linguísticos inacessíveis por causa do efeito do tempo.

Ademais, o já mencionado princípio uniformitarista de Labov (1994) contribui com a teoria da deriva, dispensando a necessidade de dispor de vastos registros históricos para entender a deriva de uma língua, ao permitir que se infira o passado dela pelos processos em curso no presente. Se esse princípio estiver correto, podemos inferir a deriva do PB apenas a partir de resquícios de seus antepassados linguísticos tendo como contraponto estudos variacionistas sincrônicos. Em partes, é o que vêm tentando fazer Marta Scherre e Anthony Naro.

Enfim, para encerrar este tópico, devo afirmar que as versões fortes de ambas as teorias apresentam problemas epistemológicos. Por um lado, a hipótese crioulista vê a sua versão forte quebrada no momento em que a condição necessária de uma crioulização prévia para explicar as características distintivas do PB torna-se apenas uma possibilidade (e não mais uma necessidade). Com isso, resta-lhe a versão fraca: as características que distinguem o PB podem ter sido induzidas por um processo de crioulização prévio. Por outro lado, a versão forte da hipótese derivista é quebrada uma vez que o cerne da sua capacidade heurística (o conceito de deriva) consiste em algo vago, de difícil observação. Resta-lhe buscar pequenos insights internalistas, descrevendo mudanças funcionalmente guiadas etc. 


\title{
5 SOBRE O SETTLING DO PORTUGUÊS BRASILEIRO
}

Ao analisar os principais fatos linguísticos invocados pela hipótese crioulista, tentei mostrar que nenhum deles necessita de uma crioulização prévia para ser explicado. Alguns deles constituem inovações radicais (por exemplo, as estratégias de relativização e as interrogativas sem movimento), porém outros remetem a claros casos de conservadorismo. Isso, ao que me parece, coloca uma nova questão no debate: por que o PB é, ao mesmo tempo, radicalmente conservador e inovador?

Dahl (2006) mostrou recentemente que conservadorismo e inovação parecem estar altamente relacionados. Olhando para certos dialetos suecos, ele observou paralelos entre características conservadoras e inovadoras desses dialetos e concluiu o seguinte:

\begin{abstract}
[These features] originally had a shared larger distribution but were later pushed back by essentially the same kinds of processes. This means in its turn that the innovations must be old enough to have been in place already when these processes took place. Given the general geographical picture, it appears that both the original spread of the innovative features and the later processes that obliterated them started in the same region $[\ldots]$. (DAHL, 2006, p. 221). ${ }^{6}$
\end{abstract}

Portanto, características conservadoras e inovadoras de uma dada variedade linguística podem ser geradas pelos mesmos processos de acordo com a formação histórica daquela variedade. No caso do português do Brasil, isso faz muito sentido se considerarmos como se processou a colonização portuguesa por aqui refiro-me à discussão sobre os aloglotas portugueses no início da colonização do Brasil, discussão que suspendi no fim do tópico 2 deste ensaio. Antes de desenvolver esta hipótese, porém, julgo conveniente invocar o conceito de settling proposto por Seuren (2013).

Seuren entende que, sendo a língua parte de uma realidade social (como já explicado no tópico 1 deste ensaio), processos de gramaticalização, desgramaticalização, reanálise, mudança funcionalmente guiada, entre outros, tornaram-se propostas legitimadas na linguística moderna, mas o que raramente se percebe é que tais processos não teriam qualquer consequência se não fossem iniciados e subsequentemente aceitos por uma dada comunidade linguística, "[...] que reina soberana em questões relacionadas à identidade e à forma específica de qualquer língua ou variedade linguística." (SEUREN, 2012, p. I). Por isso, para Seuren, falar sobre uma língua ou sobre mudança linguística sem levar em consideração o processo de aceitação social (settling) daquela língua é como falar sobre leis sem levar em consideração o papel do legislador.

In simple terms, settling occurs when certain ways of speaking 'catch on' in a society o community or a subgroup thereof. Settling phenomena are historical processes of a social or, if you prefer, sociolinguistic nature. They are an indispensable element in sociopsychological processes whereby some attitude or behavioural manifestation suddenly gets viewed as 'standard' or 'the thing to do'. It does not look as if social psychology has much to say about the highly elusive turning point in social reality (called 'catastrophe' in the mathematics of dynamical systems), at which an innovation becomes accepted as 'standard' for any given group or subgroup. Power relations, fascination and group solidarity seem to be important factors guiding any settling processes, but precisely how and to what extent remains to be sorted out. ${ }^{7}$

A aceitação social acontece no momento em que os indivíduos sentem coletivamente que estão seguindo o (velho ou novo) padrão, quando pensam ou se comportam de uma determinada maneira. O fenômeno de aceitação social da língua define o que os falantes veem como a identidade da sua língua ou variedade linguística, paralelamente à sua identidade social. Normas linguísticas socialmente válidas em grande escala são resultado de processos de aceitação social (settling).

\footnotetext{
6 [Essas características $]$, originalmente, compartilharam uma distribuição mais ampla, mas foram posteriormente deixadas para trás essencialmente pelos mesmos tipos de processos. Isso significa, por sua vez, que as inovações devem ser antigas o suficiente a ponto de já existirem quando esses processos ocorreram. Dado o mapa geográfico geral, parece que tanto a distribuição original das características inovadoras quanto os processos posteriores que as obliteraram começaram na mesma região […].

7 Em outras palavras, o settling ocorre quando certos modos de falar "pegam” em uma sociedade ou comunidade ou um subgrupo dela. Os fenômenos de settling são processos históricos de natureza social ou, ainda, sociolinguística. Eles são um elemento indispensável nos processos sociopsicológicos por meio dos quais uma atitude ou manifestação comportamental passa, de repente, a ser vista como "padrão" ou "a coisa a se fazer". Ao que parece, a psicologia social não tem muito a dizer sobre o ponto de mudança altamente elusivo na realidade social (chamado de "catástrofe" na matemática de sistemas dinâmicos), no qual uma inovação se torna aceita como "padrão" para qualquer grupo ou subgrupo. Relações de poder, fascinação e solidariedade coletiva parecem ser fatores importantes no direcionamento de quaisquer processos de settling, mas precisamente como e até que ponto eles são determinantes ainda está por ser descoberto.
} 
Por muito tempo, a tradição de linguística românica que se ocupava do PB pressupôs que os imigrantes portugueses que colonizaram o Brasil provieram do sul de Portugal. Com base nesse pressuposto, acreditava-se que o PB derivava da variedade meridional do PE, o chamado algarvio-alentejano. Silva Neto (1979 [1952], p. 181-187), porém, derrubou tal pressuposto, ao vasculhar documentos migratórios de diversas fontes e demonstrar que colonizaram o Brasil imigrantes provenientes de todas as regiões de Portugal, sem predominância de nenhuma região específica. Portanto, reuniram-se no Brasil, no início da colonização, falantes das variedades do sul, do centro, do norte e do eixo Coimbra-Lisboa. Diante desse quadro, inferir as consequências do contato dessas variedades dialetais nos leva a remontar o settling do PB.

Nos termos de Silva Neto (1979 [1952], p. 588, grifo meu),

Quando entram em convivência dois indivíduos que, embora do mesmo domínio linguístico, pertencem a regiões diferentes, dá-se como que um acordo tácito que elimina as características mais salientes da pronúncia de um e de outro. Assim se reduzem as asperezas e se obtém um instrumento dúctil e maleável, harmonioso, capaz de servir plenamente aos interesses da intercomunicação. Assim, eliminamse os localismos em favor do geral.

O "acordo tácito" inferido por Silva Neto não é outra coisa senão o processo de aceitação social de uma forma linguística conceituado por Seuren. Assim, o settling ocorrido entre os aloglotas portugueses levou à criação de uma língua-geral, misto de diferentes variedades dialetais portuguesas. Dessa língua-geral acordada entre os aloglotas portugueses, teria derivado o PB.

Embora a teoria do predomínio dos povos do sul de Portugal na colonização do Brasil não pareça corresponder à verdade, em geral, tanto o $\mathrm{PB}$ como o espanhol americano apresentam numerosas semelhanças com a língua falada nas zonas meridionais da Ibéria. A explicação para essa semelhança estaria na própria formação dos falares ibérico-meridionais:

Acreditamos, pois, que, na Colônia, portugueses de todas as partes se fundiram em contacto e interação, eliminando, expurgando os difíceis fonemas do Norte, os tipicismos que podiam levar à sanção do ridículo, as particularidades que diante da língua comum se poderiam considerar "rusticismos". Assim, de certo modo, se repetia, no Brasil, aquele peneiramento e aquela seleção que se operara durante a reconquista. É que tanto o sul de Portugal como o Brasil são regiões de colonização, isto é, regiões onde entraram em contacto (e conseqüente interação) falares pertencentes a uma estrutura lingüistica comum. Assim, a pronúncia do Sul já era, ela própria, o resultado do contacto entre portugueses de todas as partes do País. A fonética do Norte duas vezes se encontrou com a do Sul: durante a Reconquista e durante a obra da colonização ultramarina (SILVA NETO, 1979 [1952], p. 588).

E Silva Neto ainda acrescenta:

$[\ldots .$.$] as áreas de colonização, como já ensinava Schuchardt em 1870, caracterizam-se por grande unidade$
lingüística, visto nelas se cruzarem e entrechocarem povoadores de todas as proveniências. Por isso
lembrava ele que o Inglês da América do Norte, média dos vários dialetos que com os povoadores
atravessaram o oceano, é o denominador comum, uma espécie de Koiné. Anos mais tarde, em 1892, Lenz
observava o mesmo caráter no Espanhol chileno, onde se dera uma sprachliche Ausgleichung (nivelação
linguística). À proporção que progredia o estudo das línguas transplantadas ia-se confirmando esse
princípio, que Meyer-Lübke generaliza ao estudar o Francês canadense (SILVA NETO, 1979 [1952], p.
592).

Portanto, parece razoável admitir que o PB se assemelhe ao PE meridional por ter passado, assim como este, por um processo de nivelamento linguístico decorrente de cruzamentos sociais e consequente interação linguística, o que concedeu à variedade meridional certa vantagem estrutural na imposição dos seus traços em solo brasileiro. Entretanto, Silva Neto e outros linguistas que já tentaram analisar a origem dos traços que permaneceram na língua-geral brasileira se concentraram principalmente no plano fonético-fonológico, e não avançaram para o plano sintático, por exemplo, onde se encontram a maior parte das inovações do PB.

Aqui, retomo a questão que coloquei antes: por que o PB é ao mesmo tempo radical (inovador) e conservador? Se a correlação entre inovação e conservadorismo percebida por Dahl (2006) estiver certa, isto é, se características conservadoras e inovadoras de uma variedade linguística tiverem origem nos mesmos processos históricos, não serão também as características inovadoras do $\mathrm{PB}$ (e não apenas os conservadorismos) fruto do settling do $\mathrm{PB}$, que envolveu praticamente todas variedades dialetais portuguesas, inclusive aquela que já tinha sofrido nivelação linguística (a meridional)? Além disso, 
considerando que a variedade meridional teria prevalecido no settling do $\mathrm{PB}$, por que ninguém nunca considerou que os dialetos meridionais também tiveram sabidamente processos de crioulização - lembremos dos dialetos moçárabes! - em sua gênese?

ILARI e BASSO (2006) parecem não desprezar a importância do settling linguístico desempenhado pelos aloglotas portugueses ao defender que o português falado no Brasil, nos primeiros séculos de colonização, sofreu um intenso processo de simplificação gramatical. Isso poderia explicar, por exemplo, as estratégias de relativização do PB. SCHERRE e NARO (2007), ao estudar paralelos entre variações de concordância no Brasil e no sul de Portugal hoje em dia, também contribuem indiretamente para a compreensão desse fenômeno.

De qualquer forma, acredito que os resultados do acordo tácito entre os aloglotas portugueses que povoaram o Brasil não vêm sendo apropriadamente avaliados no recente debate sobre a formação do PB. Considerar a co-ocorrência de conservadorismos e inovações radicais como frutos desse mesmo processo pode ser uma alternativa para esclarecer as causas das características que distinguem a língua do Brasil.

\section{CONCLUSÕES}

As conclusões deste artigo podem ser organizadas em três pontos. Em primeiro lugar, busquei mostrar que, das três hipóteses já surgidas para explicar a gênese do português brasileiro - o biologismo linguístico, a hipótese crioulista e a hipótese derivista - apenas as duas últimas ainda sobrevivem no debate. O biologismo linguístico caiu na obsolescência à medida que sua tese foi destruída: a língua não é um fato biológico, mas um fato social, sujeito também a arbitrariedades humanas e não apenas ao determinismo da natureza.

Em segundo lugar, foi minha intenção mostrar que as versões fortes das duas hipóteses ainda vivas no debate - a hipótese crioulista e a hipótese derivista - têm ambas problemas epistemológicos que podem invalidá-las. Do lado crioulista, nenhum fato linguístico invocado por seus defensores como características distintivas do PB pode ser admitido como resultado necessário de crioulização prévia. Com isso, resta-lhe a versão fraca: as características que distinguem o PB podem ter sido induzidas ou catalizadas por um processo de crioulização prévio. Do lado derivista, o cerne da sua capacidade heurística (o conceito de deriva) consiste em algo vago, de difícil observação. Resta-lhe, então, buscar pequenos insights internalistas, descrevendo mudanças funcionalmente guiadas etc.

Por fim, em terceiro lugar, a fim de contribuir com a construção da versão forte de uma teoria que pretenda explicar a gênese do PB, tentei recolocar no debate uma questão um pouco negligenciada nos últimos anos: o papel dos aloglotas portugueses que colonizaram o Brasil. Tais imigrantes trouxeram consigo diferentes variedades dialetais e, para se comunicar, tiveram de promover um settling linguístico (SEUREN, 2013) em direção a uma variedade comum, supradialetal. Essa questão foi bastante discutida por SILVA NETO (1950; [1952] 1979) na década de 50, mas depois caiu no esquecimento. Ele defendeu que, embora a variedade portuguesa meridional não tenha tido a maioria de falantes no Brasil (ao contrário do que muitos já alegaram), essa variedade prevaleceu às demais porque já tinha passado por nivelamentos (principalmente no plano fonético-fonológico) no período da Reconquista, alguns séculos antes.

Para reforçar a importância do settling do PB pelos aloglotas portugueses e recolocar essa questão no debate atual, recorri a um trabalho de DAHL (2006). Este autor, ao estudar processos de gramaticalização em vernáculos escandinavos, descobriu que dialetos que apresentam, ao mesmo tempo, um alto grau de conservadorismo e inovação - como é o caso do PB - passaram essencialmente pelos mesmos tipos de processo em um dado momento histórico, sendo que as motivações, tanto para as tendências inovadoras quanto para as tendências conservadoras, tiveram origem naquele momento. DAHL (2006) consegue provar que tais fatos históricos são necessários para explicar a emergência de certas estruturas gramaticais. Se isso for verdade, deve ter ocorrido na formação do PB algo semelhante ao que ocorreu naqueles dialetos escandinavos, algo capaz de cristalizar conservadorismos e fazer surgir inovações na língua. Defendo que tal evento tenha sido o settling do PB provido pelos aloglotas portugueses em solo brasileiro, que nivelou as variedades dialetais imigradas (com predomínio da variedade meridional de Portugal) e favoreceu um processo de simplificação gramatical. 


\section{REFERÊNCIAS}

ALMEIDA, J. M. P.; LIMA-SALLES, H. M. M. Análise das estruturas relativas do português do Brasil. In: CONGRESSO INTERNACIONAL DA ABRALIN, 7., Curitiba, 2011. Anais... Curitiba: Abralin, 2011. p. 1965-1978.

BAXTER, A. A contribuição das comunidades afro-brasileiras isoladas para o debate sobre a crioulização prévia: um exemplo do estado da Bahia. In: ANDRADE, E. d'; KIHM, A. (Eds.). Actas do colóquio sobre crioulos de base lexical portuguesa. Lisboa: Colibri, 1992. p. 7-35.

BAXTER, A. A concordância de número. In: LUCCHESI, D.; BAXTER, A.; RIBEIRO, I. (Orgs.). $O$ Português Afro-Brasileiro. Salvador: EDUFBA, 2009. p. 269-294.

CASTILHO, A. O Português do Brasil. In: ILARI, Rodolfo. Linguística Românica. 3. ed. São Paulo: Ática, 1999.

CUNHA, C. Conservação e Inovação no Português do Brasil. O eixo e a roda, Belo Horizonte, v. 5, 1986, p. 199-230.

DAHL, Ö. Grammaticalization in the North: noun phrase morphosyntax in Scandinavian vernaculars. Stockholm: Stockholm University, 2006.

EIDELWEIN, M. A próclise dos pronomes oblíquos átonos em posição inicial: uma perspectiva linguísticohistórica. 2010. 62 f. Monografia (Licenciatura em Letras) - Universidade Federal do Rio Grande do Sul, Porto Alegre, 2010.

HOLM, J. Creole influence on Vernacula Brazilian Portuguese. In: GLENN, Gilbert (Ed.). Pidgin and creole languages. Honolulu: University of Hawai Press, 1987. p. 406-429.

HUBER, J. Gramática do português antigo. Trad. port. de Maria Manuela Gouveia Delille. Lisboa: Gulbenkian, 1986 [1933].

ILARI, R; BASSO, R. M. O português da gente: a língua que estudamos, a língua que falamos. São Paulo: Editora Contexto, 2006.

LABOV, W. Principles of linguistic change - Volume 1: Internal factors. Oxford: Blackwell, 1994. (Language in Society 20).

LUCCHESI, D.; BAXTER, A.; RIBEIRO, I. (Orgs.). O Português Afro-Brasileiro. Salvador: EDUFBA, 2009.

LUCCHESI, D.; LOBO, T. Aspectos da sintaxe do português brasileiro. In: FARIA, I. H., PEDRO E. R., DUARTE, I., GOUVEIA, C. A. M. (Orgs.). Introdução à lingüística geral e portuguesa. Lisboa: Editorial Caminho, 1996. p. 303-311.

LUCCHESI, D.; MENDES, E. P. A flexão de caso dos pronomes pessoais. In: LUCCHESI, D.; BAXTER, A.; RIBEIRO, I. (Orgs.). O Português Afro-Brasileiro. Salvador: EDUFBA, 2009. p. 471-488.

LUCCHESI, D. Variação e norma: elementos para uma caracterização sociolingüística do português do Brasil. Revista Internacional de Lingua Portuguesa, Lisboa, n. 12, p. 17-28, 1994.

MATTOS E SILVA, R. V. Ensaios para uma sócio-história do português brasileiro. São Paulo: Parábola, 2004.

MCWHORTER, J. The Afrogenesis hypothesis of plantation creole origin. In: HUBER, M.; PARKVALL, M. (Eds.). Spreading the word. London: Westminster University Press, 1999. p. 111-152.

MELLO, G. C. A Lingua do Brasil. 2. ed. Rio de Janeiro: FGV, 1971.

NARO, A. A História do "e" e do "o" em Português. Um estudo de Deriva Linguística. Language, Washington, v. 47, n. 3, p. 616, 1971.

NOLL, V. O Português Brasileiro. Trad. de Mário Eduardo Viaro. São Paulo: Globo, 2008.

PAIVA BOLÉO, M. Estudos de linguística portuguesa e românica. Coimbra: Acta Universitatis Conimbrigensis, 1974 .

PARKVALL, M; LÓPEZ, L. Á. Português Vernáculo Brasileiro e a Hipótese da Semi-Crioulização. Revista da ABRALIN, Natal, v. 2, n. 1, p. 111-152, 2003. 
PESSOA DE CASTRO, Y. A sobrevivência das línguas africanas no Brasil: sua influência na linguagem popular da Bahia. Afro-Asia (UFBA), Salvador, v. 4-5, p. 25-34, 1967.

RIBEIRO, I. As sentenças relativas. In: LUCCHESI, D.; BAXTER, A.; RIBEIRO, I. (Orgs.). O Português Afro-Brasileiro. Salvador: EDUFBA, 2009. p. 185-208.

SCHERRE, M. M. P.; NARO, A. Origens do português brasileiro. São Paulo: Parábola Editorial, 2007.

. Variable concord in portuguese: the situation in Brazil and Portugal. In: MCWHORTER, J.

(Org.). Language change and language contact in pidgins and creoles. Amsterdam; Philadelphia: John Benjamins, 1999. p. 235-255.

SEUREN, P. A. M. From whorf to montague. Oxford: Oxford University Press, 2013.

SILVA NETO, S. S. História da língua portuguesa. Rio de Janeiro: Presença, 1979 [1952].

Introdução ao estudo da língua portuguesa no Brasil. Rio de Janeiro: Presença, 1950.

VENNEMANN, T. An explanation of drift. In: LI, C. N. (Org.). Word order and word order change. Austin: University of Texas Press: 1975. p. 269-305.

Recebido em 12/04/13. Aprovado em 31/o8/13. 